\title{
Effect of Lattice Apron Age on the Quality of Compact Ring-Spun Yarns
}

\author{
Shahriar Raian and Jamal Hossen* \\ Department of Textile Engineering, Ahsanullah University of Science and Technology, Dhaka -1208, Bangladesh \\ *Corresponding author: Jamal Hossen, Department of Textile Engineering, Ahsanullah University of Science and Technology, Dhaka-1208, \\ Bangladesh
}

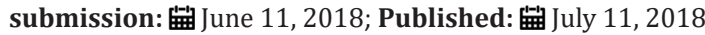

\begin{abstract}
The compact spinning technique is one of the major improvements of classical ring spinning which has superior yarn structure and quality in terms of hairiness and strength. With a view to achieve, this paper reveals the significant correlation of differently aged lattice aprons of sussen compact spinning attachment with different yarn quality characteristics and fitting both simple and multiple linear regression equation. The $100 \%$ cotton compact yarns of 30's Ne are spun with differently aged lattice apron from the same cotton fibers, same roving and on the same spindles of the same ring frame with keeping the machine speed and doff length constant. The unevenness of mass variation U\%, imperfection index (IPI), hairiness (H), countstrength-product (CSP), tenacity, elongation\% of yarns are tested with quality control equipment and analyzed. Comparing with the new to 10-month aged lattices apron the evenness, strength, imperfections, and hairiness of produced yarns show decrement trends with an increment in elongation. The established multiple linear regression fitting line elicits the manufacturers to predict the quality of compact ring spun yarns.
\end{abstract}

Keywords: Compact spinning; Ring frame; Lattice apron; Uster evenness tester 5; Multiple linear regression analysis

\section{Introduction}

Yarn manufacturing is the first stage of textile processing that converts the fibers into yarns. It is one of the subsectors of backward linkage of clothing industries [1]. The yarns can be classified on the basis of spinning techniques like ring, compact, rotor, air jet and friction [2]. Nowadays ring-spinning is mostly used because of its simplicity, flexibility and economical in commercial production $[3,4]$. The usages of ring spinning in about $90 \%$ of the world spinning industry make it the most popular method for short staple fiber [5]. Compact spinning attachment is trumped among various techniques not only for improvement of yarn quality but also meeting the customer's criteria and improves subsequent processes weaving, knitting, and dying in terms of increasing productivity [6-8]. It is a fundamental modification of traditional ring spinning because it allows to condense the fiber bundle as well as to decrease the spinning triangle $[9,10]$. As a result, the yarns spun on the compact spinning system are characterized by higher tenacity, higher elongation-at-break [11]. Compact yarns have higher tenacity due to higher rate and amplitude of fiber migration [12]. Not only cotton yarns but also the compact spun worsted yarns also have the advantages of better quality and different surface specifications, that will help to improve further processing and increase the production rate and overall meeting the competitive advantages to survive in the market [13-17]. The hairiness of yarn significantly reduced in compact yarns as well as improvement of strength and appearance $[18,19]$. As it requires only some modification of traditional ring spinning, the researchers consider it as a new spinning technique because of its some revolutionary feature like superior yarn structure and quality in respect to hairiness and strength $[20,21]$.

Since 1993 investigation was going on to introduce first industrial compact spinning frame at ITMA 1995 [22]. Between pneumatic and mechanical compacting, pneumatic is the most popular where negative airflow, used to condense the fiber bundle and decrease the spinning triangle [23]. Twist imparted by the traveler travels against the direction of yarn movement to the nip line of the front rollers as well as the flow of fibers [24,25]. A triangular bundle of untwisted fibers just at the exit of front roller is called the spinning triangle and is created due to the variation of tensions with fiber migration [26]. The path between roving to yarn cop package and the arrangement of various parts is known as spinning geometry that has a significant effect on the yarn breakage and strength, generation of fly, yarn hairiness and yarn structure [27]. Spinning triangle causes greater waste of fibers, lower tenacity, poorer appearance and greater hairiness of the spun yarn [28] and so inversely affects yarn qualities [29]. Another negative side is that spinning triangle influences the distribution of fiber tension spun yarns quality [30]. As spinning triangle is a major problem in ring spinning so it is very necessary to eliminate it. Dr. Fehrer eliminated the spinning triangle by condensing the fiber assembly in the spinning triangle zone. Consequently, it increases 
the participation of outer edge fibers in the yarn body, which allows same yarn strength with $20 \%$ less twist as a result increase in spinning production $[31,32]$. To eliminate twisting triangles with the help of air suction an additional attachment is furnished over ring spinning frame [4]. It is achieved by pneumatic compacting devices such as suction and perforated revolving apron or drum in front zone of the drafting system [33].

Different manufacturers offer a numerous design but the basic principle is same as condensing the fiber strand at the end of the draft region pneumatically [4]. Nowadays the most common producers of this attachment are Zinser, Toyota, Rieter, Roscraft, and Suessen. Among them, Rieter's Com 4 and Suessen' Elite are the leading positions in compact spinning with almost the same in yarn quality $[19,34]$. The condensing zone for most of the producers comprises a stationary sliding surface having a suction slot, over which the fiber strand is transported by an air-permeable transport belt [35]. Lattice apron and perforated drum are excessively used as the condensing devices in compact spinning systems [36,37]. Like the Rieter compact spinning system consists of a perforated drum, air guide element and suction system. The perforated drum condenses all the fibers after the main drafting through air currents which control the fibers in the spinning triangle region [33]. In Sussen Elite compact spinning system introduces an additional drafting zone in the 3 over 3 rollers double apron drafting system with air permeable lattice apron and suction slot. This air permeable lattice apron slides over the suction slot to condense the fibers. Numerous studies have been carried out on this attachment such as.

Kremenakova et al. [38] investigated on compact yarn structure and made a conclusion on the radial and effective packing density, effective yarn diameter of the ring and compact yarns etc. Yilmaz et al. [39] revealed fiber distribution through the cross-sections of compact yarns and their packing density to understand the internal structures, strength, extensibility, appearance, compactness of different compact spun yarns. Loganathan, Mallyah, \& Ramachandran [40] studied on the production of regular carded ring spinning, regular carded compact spinning, and d-type slot carded compact spinning with three different twist level to analyze the effect of twist on mean fiber position, root mean squared (RMS) deviation, migration intensity and yarn diameter. Wang [41] investigated a systematic analysis to find out the causes of increasing strength of compact siro spun yarn, evenness and the reduction of yarn hairiness. Zou \& Cheng [42] studied on fiber motion trajectory in an airflow field of compact spinning with a perforated drum to determine the dynamic model of fibers by using the flow rule and solve the fiber motion trajectory through the condensing zone by using Matlab program. Zou et al. [43] studied on the pattern of flow in the condensing zone and flexible fiber trajectory is simulated by a specially designed Matlab program routine to make an explanation of pneumatic condensing mechanism in the condensing zone. Lu [44] studied on compact siro spinning with a lattice apron to observe the influence of airflow on fiber movement. A detailed study was conducted by Han et al. [45] on simulation and characterization of the flow field in the condensing zone are made by computational fluid dynamics software which mainly includes the distribution rules of static pressure and velocity to explain the theoretical basis for optimum compact siro yarn properties in the practice of production. Fu et al. [46] developed a pneumatic compact spinning system with an arc-shaped suction slot with lattice apron to determine additional twists inserted during condensing. Khurshid et al. [47] investigated the influence of pneumatic compact spinning system by using Rieter $\AA$ K-44 compact spinning with coarse, medium and fine linear densities of both ring siro and compact siro spun yarns hence to compare irregularity with respect to mass, IPI, hairiness and tensile properties between two types of siro yarn.

In above mentioned all the studies the focal point of interest were related to compact spinning attachments, the role of different components, methods of different condensing, comparison with different compacting techniques as well as their effect on fiber strands quality and their competitive advantages. However, for the first time, this paper studied on differently aged lattice aprons of compact attachment of ring frame on the quality of compact spun yarns and institutionalizes the correlation between age of lattice apron and yarn quality. This relationship will probably indicate the suitable lifetime of lattice apron in regard to achieve optimum quality assurance.

This section of this study reveals different technical and theoretical aspects, related literature reviews, experimental findings, and background study. Section 2 covers materials and methods used in this experiment. Data analysis, results, and discussion with the construction of multiple linear regression equations are illuminated at section 3 . Finally, section 4 illustrates conclusion and recommendation for future work.

\section{Materials and methods}

\section{Properties of cotton fibers}

Table 1: Important fiber properties.

\begin{tabular}{|c|c|}
\hline Fiber Properties & Value \\
\hline Upper Half Mean Length UHML (mm) & 28.18 \\
\hline Fineness (MIC) & 4.33 \\
\hline Uniformity Index (UI \%) & 82.8 \\
\hline Strength, Tenacity (cN/tex) & 31.5 \\
\hline Short Fiber (SF \%) & 8.1 \\
\hline Spinning Consistency Index (SCI) & 134 \\
\hline
\end{tabular}

Table 2: Spinning particulars.

\begin{tabular}{|c|c|}
\hline Parameters & Value \\
\hline Yarn count (Ne) & 30 \\
\hline Yarn Twist (TPI) & 21 \\
\hline Spindle speed (rpm) & 19,000 \\
\hline Traveler number & $4 / 0$ \\
\hline Roving hank (Ne) & 0.8 \\
\hline Ring diameter (mm) & 40 \\
\hline
\end{tabular}


As a raw material, Zambian cotton fiber was used to produce $100 \%$ cotton 30's Ne carded knitted yarn. Fiber properties were tested by USTER HVI Spectrum and these are processed in various machinery to produce ultimate yarn. The properties of fibers and different spinning particulars are shown in Table $1 \& 2$.

\section{Sussen compacting attachment}

Sussen is a worldwide successful pioneer of supplying the compact spinning technology since the ITMA 1999 in Paris because of its some useful characteristics like as optimal and high consistency in yarn quality, easy handling, universally applicable and easily be retrofitted to any ring-frame. To condense the just drafted fiber strand, it uses aerodynamic condensation. There are several parts which are suited just after front drafting roller such as lattice apron, Eli-tube (with some suction slot to condense fiber strand by aerodynamic suction as well as to suck some microdust incorporated with strands), Eli-top and Eli-rod (to tightly attach the lattice apron on Eli-tube). Different elements of compact spinning attachment, shown in Figure $1 \& 2$ shows the compact spinning attachment, retrofitted on ring frame.

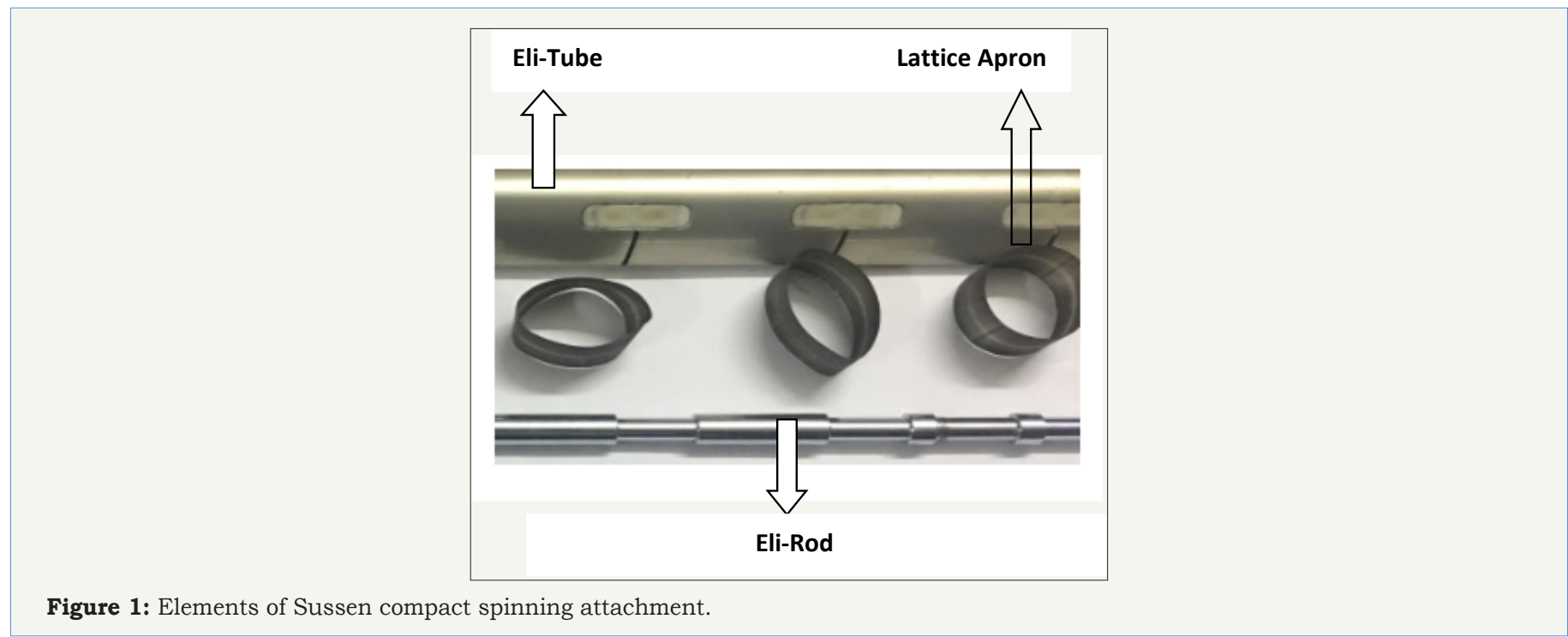

Figure 1: Elements of Sussen compact spinning attachment.

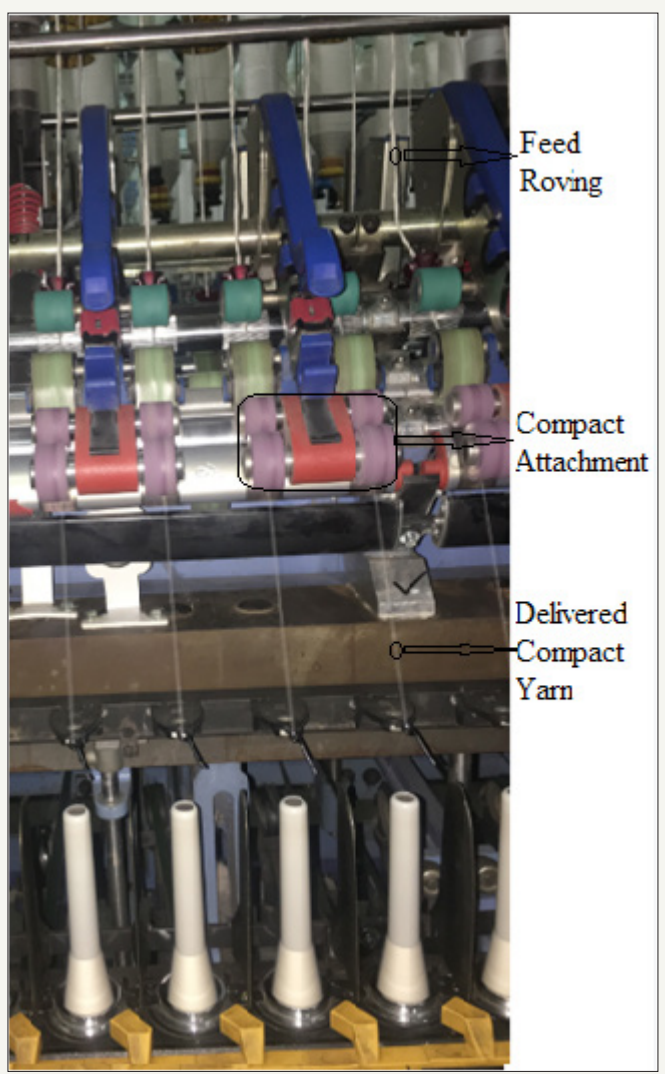

Figure 2: Sussen compact spinning attachment. 


\section{Lattice apron}

Nowadays, lattice apron is the most popular component for compact spinning [48] which should be designed appropriately. It is circular in size with around 3000 holes per square $\mathrm{cm}$, which doesn't allow the fibers to be sucked in but micro-dust can be sucked out from the yarn. Its dimension is $36.5 \mathrm{~mm} \times 2 \mathrm{~mm} \times 1 \mathrm{~mm}$. It is situated over a grooved tube known as Eli-tube just after the classical 3 over 3 drafting roller [42]. Slightly faster moving of it provides a small tension draft leading to optimal fiber orientation and axial tension.

\section{Methodology}

The study was conducted on a ring frame in ayarn manufacturing company where 30's Ne carded knitted yarns were produced. First of all, fiber properties of the concerned lot were collected by testing in USTER HVI Spectrum. The materials were then passed through carding, breaker draw frame, finisher draw frame, and simplex. From simplex five roving samples of five specific spindles were collected for this research after checking quality parameters these rovings were fitted onto the roving holders of the ring frame for 5 specific spindles. New lattice aprons were set in ring frame and yarns were spun accordingly until their full doffs (approx. 2.5hrs). The above whole procedure was repeated for other 10 differently aged (one, two, three, four, five, six, seven, eight, nine and ten month respectively) lattice aprons keeping all setting from the blow room to ring frame unchanged. The yarn samples were taken to quality control department for testing with Uster Tester-5 (UT-5). The correlation of differently aged lattice aprons with yarn quality parameters U\%, IPI, Hairiness, CSP, Tenacity, and Elongation\% was established with the appropriate construction of simple linear regression equation. Finally, multiple linear regression equations were constructed based on the age of lattice apron and yarn quality.

To get reliable test result with the minimum variability of 5 spindles of the same compact spinning machine was used and obtained 55 samples of the same fineness of yarn and keeping all the parameters same by using 11 differently aged lattice aprons. The yarn tests were carried out on Evenness Tester (UT-5) by ASTM D1425-96 for $\mathrm{U}_{\mathrm{m}} \%$ and hairiness by ASTM D 5647-01, Lea Strength Tester by ASTM D 1578-93, USTER Tensojet-4 (For single yarn strength test), and Electronic twist tester (For twist test) by ASTM D1423-02. Above all tests were done under standard atmospheric conditions $27 \pm 2{ }^{\circ} \mathrm{C}$ and $65 \%$ RH. Then by using both multiple and single regression analysis the correlation between age of lattice apron with yarn quality was observed and was developed multiple linear regression equations by using these properties in a relationship with the ages of the lattice aprons.

\section{An Overview of Correlation and Regression Analysis \\ Correlation analysis}

Correlation Analysis is a group of statistical techniques to measure the association between two variables known as a dependent and independent variable. The dependent variable is the variable being predicted or estimated. The Independent Variable provides the basis for estimation. It is the predictor variable. Such as to determine the relationship between ring yarn properties and the fiber properties obtained by AFIS [49]. A Scatter Diagram is used to portray the relationship between two variables.

The correlation coefficient is the representation of the degree of linear relationship between two variables [50]. It is represented by "r". The value lies between -1 to +1 .

Characteristics of the correlation coefficient

- Identify by the lowercase letter $r$ and ranges from -1 to +1 .

- $\quad$ Shows the direction and strength of the linear relationship between two variables.

- Near 0 and \pm 1 indicates little, strong positive and negative relationship between the variables [51].

\section{Regression analysis}

In mid to late 1800's a scientist named Galton was studied largely on an observational study on a human being and tried to find out the relationship between the heights of fathers and first sons [52]. The concept regression analysis was derived from the study of Galton. Simple (single) regression analysis simply indicates the value of a dependent variable is estimated on the basis of one independent variable whereas multiple regression analysis is something which indicates the estimation of the value of a dependent variable in terms of two or more independent variables [53]. Here, Y stands for dependent variable and $\mathrm{X}$ for the independent variable [54]. So it can be said that single regression analysis involves with one for both dependent and independent variable but we have to go for multiple regression analysis we want to estimate a value which depends on more than one independent variable.

\section{Construction of simple regression equation}

Regression Equation is an equation that expresses the linear relationship between two variables. The general form of liner Regression Equation,

$Y_{i}=a+b X$

Where, $\mathrm{X}_{\mathrm{i}}, \mathrm{Y}_{\mathrm{i}}$ represent the criterion and the predictor variable $\mathrm{a}, \mathrm{b}$ respectively are regression coefficients [55].

Step-1: Determination of Coefficient of Correlation " $r$ ".

Here, $\mathrm{r}=\frac{\sum\left(X_{i}-\bar{X}\right)\left(Y_{i}-\bar{Y}\right)}{(n-1) s_{X} s_{Y}}$

Where

$\bar{X}=$ is the mean of independent variable $\mathrm{X}$

$\bar{Y}=$ is the mean of dependent variable Y

$\mathrm{S}_{\mathrm{X}}=$ is the standard deviation of the independent variable

$\mathrm{S}_{\mathrm{X}}=\sqrt{\frac{\sum\left(X_{i}-\bar{X}\right)^{2}}{n-1}}$

$\mathrm{S}_{\mathrm{Y}}=$ is the standard deviation of the dependent variable 
$\mathrm{S}_{\mathrm{Y}}=\sqrt{\frac{\sum\left(Y_{i}-\bar{Y}\right)^{2}}{n-1}}$

And $\mathrm{n}=$ Number of samples

Step-2: Determination of Y-intercept "a"

Here, $\mathrm{a}=$ Y intercept $=\bar{Y}-\mathrm{b} \bar{X}$

Step-3: Determination of slope of the regression Line " $b$ " Here, b= Slope of the regression Line $=\mathrm{r} \frac{S_{Y}}{S_{X}}$

Step-4: Finally formation of regression equation [55].

\section{Multiple linear regression}

In multiple linear correlation and regression, additional independent variables (denoted $\mathrm{X}_{1}, \mathrm{X}_{2}$........and so on) help better explain or predict the dependent variable (Y). Almost all of the ideas in simple linear correlation and regression extend to this more general situation. However, the additional independent variables do lead to some new considerations. Multiple regression analysis can be used either as a descriptive or as an inferential technique. So far, it is one of the most popular statistical models to predict the yarn properties made from different fibers [56,57].

General form of multiple regression equation,

$$
\mathrm{Y}=\mathrm{A}+\mathrm{B}_{1} \mathrm{X}_{1}+\mathrm{B}_{2} \mathrm{X}_{2}+\ldots \ldots \ldots \ldots \ldots+\mathrm{B}_{\mathrm{n}} \mathrm{X}_{\mathrm{n}}
$$

where, $\mathrm{A}=\mathrm{Y}$ intercept

$$
\mathrm{X}_{1}, \mathrm{X}_{2}, \ldots \ldots \ldots \ldots \ldots, \mathrm{X}_{\mathrm{n}}=\text { Independent variables }
$$

\section{Results and Discussions}

Lattice apron makes a great impact on yarn qualities such as IPI values, thick places, thin places, Neps, Yarn hairiness, U\% in respect to mass, Yarn strength, CSP value, Tenacity and Elongation \%. These properties vary with varying the age of lattice apron (Table 3 ) because of condensing effect and suction of micro dust through its holes.

\begin{tabular}{|c|c|c|c|c|c|c|}
\hline Age of Lattice Aprons (Month) & $\mathrm{U} \%\left(\mathrm{X}_{1}\right)$ & IPI $\left(X_{2}\right)$ & Hairiness $\left(\mathrm{X}_{3}\right)$ & $\operatorname{CSP}\left(\mathrm{X}_{4}\right)$ & Tenacity $\left(X_{5}\right)$ & Elongation $\%\left(\mathrm{X}_{6}\right)$ \\
\hline 0 & 12.40 & 175 & 4.24 & 3001 & 20.19 & 4.28 \\
\hline 1 & 12.49 & 187 & 4.25 & 2975 & 20.18 & 4.39 \\
\hline 2 & 12.56 & 199 & 4.3 & 2920 & 20.23 & 4.41 \\
\hline 3 & 12.7 & 210 & 4.32 & 2900 & 20.15 & 4.45 \\
\hline 4 & 12.6 & 220 & 4.35 & 2890 & 20.18 & 4.44 \\
\hline 5 & 12.8 & 215 & 4.36 & 2840 & 19.95 & 4.48 \\
\hline 6 & 13.13 & 285 & 4.38 & 2830 & 19.91 & 4.5 \\
\hline 7 & 13.20 & 295 & 4.43 & 2850 & 19.88 & 4.51 \\
\hline 8 & 13.30 & 300 & 4.47 & 2866 & 19.82 & 4.52 \\
\hline 9 & 13.40 & 315 & 4.49 & 2746 & 19.56 & 4.62 \\
\hline 10 & 13.87 & 358 & 4.79 & 2363 & 19.10 & 4.87 \\
\hline
\end{tabular}

Table 3: Effect of age of lattice apron on different yarn properties.

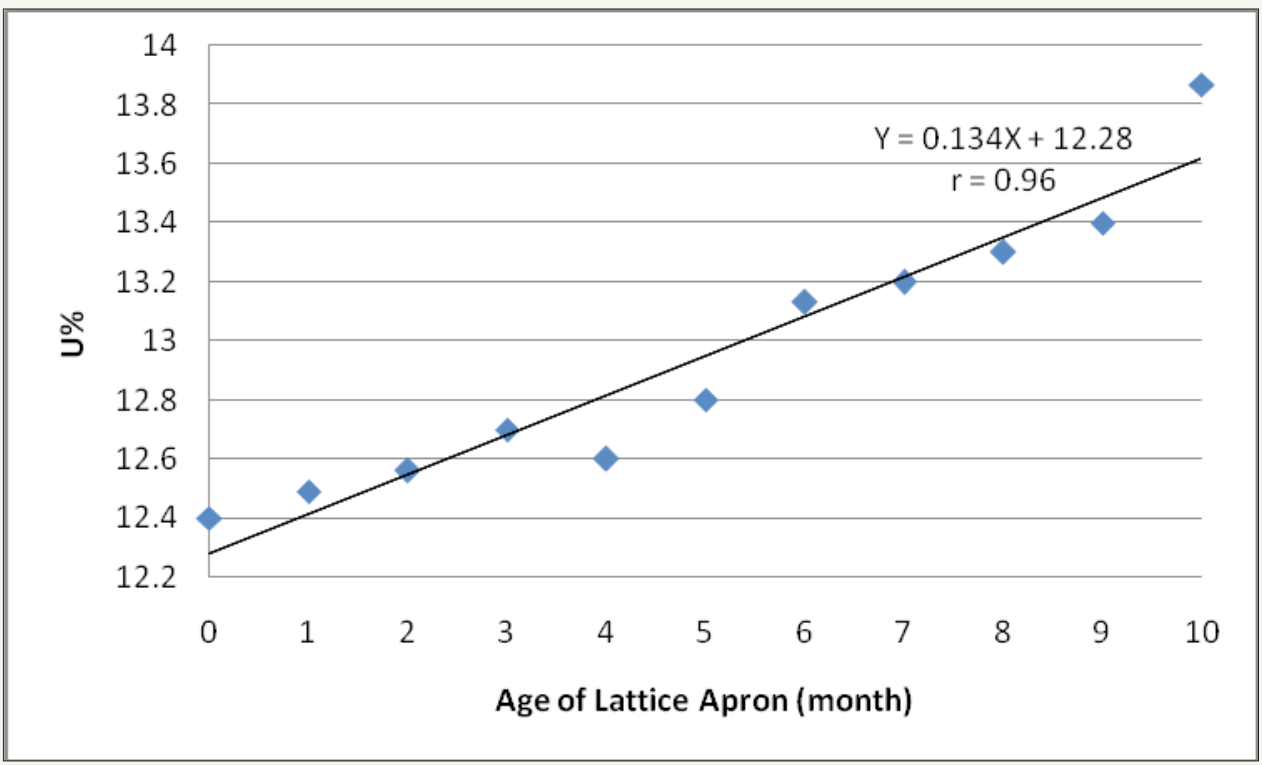

Figure 3: Relationship between U\% and age of lattice apron. 
U \% (unevenness) expresses the irregularity of sliver, roving, and yarn [58]. By using the Excel software we find the value of the coefficient of correlation, $r=0.96$ which shows the very strong positive relationship between them. This trend (Figure 3) shows due to the blocking of the holes of lattice aprons with the increase of their ages that inhibit sucking short fibers and micro dust evenly from the drafted fiber strand. Another possible explanation for that might be the weak fiber control due to the blockage of fibers underneath the perforated apron, as sometimes observed, leading to unstable compacting power and therefore uncontrolled spinning during production [20].

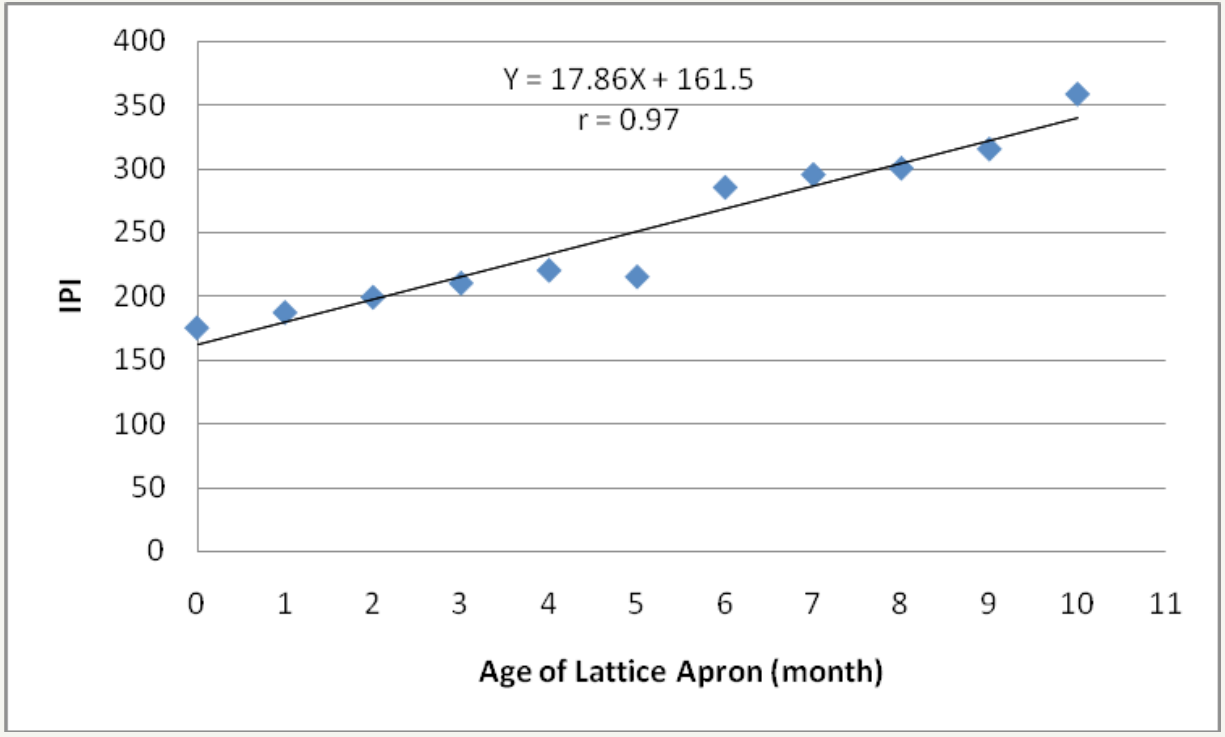

Figure 4: Relationship between IPI and age of lattice apron.

The imperfection index (IPI) is the sum of yarn thin places/ $\mathrm{km}(-50 \%)$, thick places/km (+50\%) and neps/km (+200\%) per kilometer of tested yarn for ring spun yarn $[2,59]$. Here coefficient of correlation, $r=0.97$ which indicates gradually increased of IPI with the increasing of the age of lattice aprons (Figure 4). For the age of 10 months of lattice apron, the value increased a lot. IPI is regarded as the overall defects of yarn. More IPI value of yarn means deterioration of yarn quality in terms of evenness that is usually led to lower yarn strength.

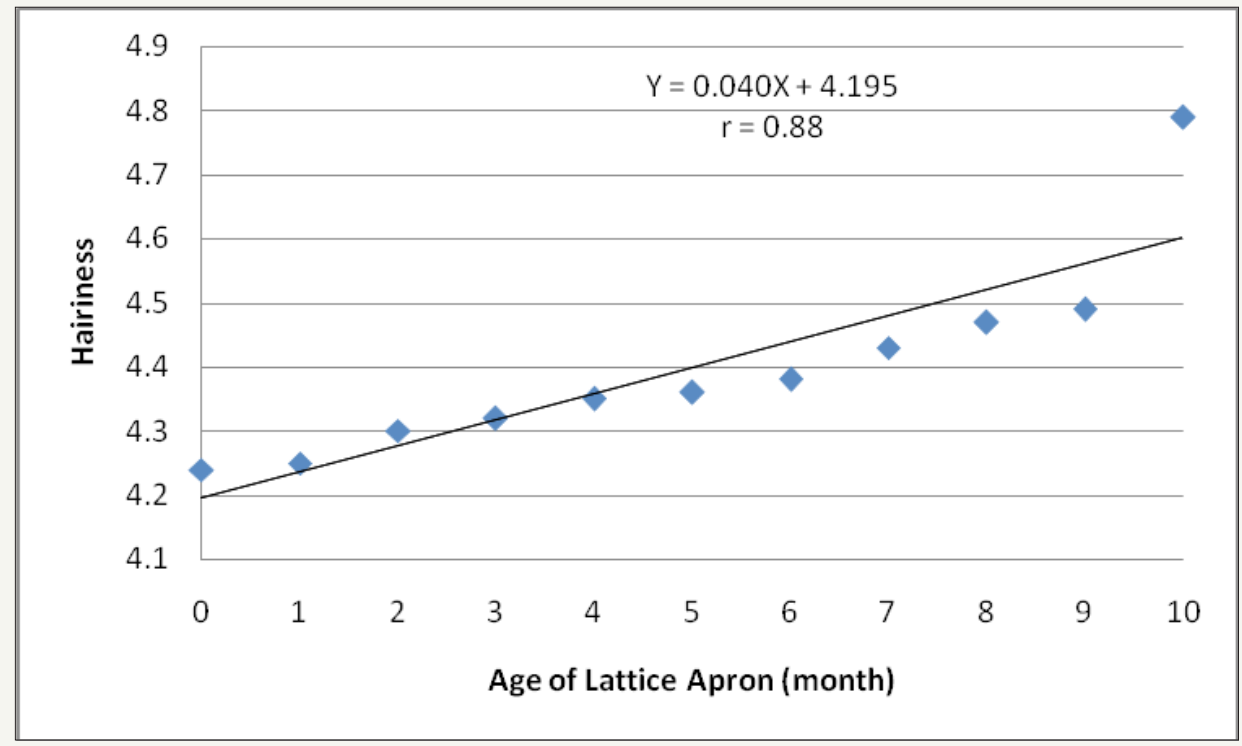

Figure 5: Relationship between hairiness and age of lattice apron.

Hairiness is defined as the total length of the protruding fibers within reference length of $1 \mathrm{~cm}$ [60]. Here, the value of $r=0.88$ shows increasing pattern because of the result of choking off the apron by short fibers and dust. The hairiness value was monotonically 
increased up to the apron age of nine months but it was significantly increased of the age of lattice aprons aged of the tenth month and above (Figure 5). CSP is an expression of lea strength of yarn. The negative value of $r=-0.78$ means the CSP value decreased (Figure 6) with the increasing the age of lattice aprons due to higher IPI.

Tenacity is defined as the theoretical length of yarn by which it breaks by its own weight when hanging vertically [61]. Here, $r=-$ 0.88 also shows inverse trend due to probably same reason as CSP (Figure 7). The elongation percentage is the ratio of elongation of the specimen to the initial length expressed as a percentage $[62,63]$. Here, the coefficient of correlation, $r=0.88$ is close to +1 so there is a strong positive relationship between them that means both values increased. The breaking elongation percentage of yarns was lowest for the new lattice aprons, gradually increased with age of aprons (Figure 8) and highest for the oldest lattice aprons. This is assumed to be due to the decrease of frictional contact among fibers (known as tightness factor) for the presence of higher numbers of short fibers and micro dust in yarns resulted from the choking of apron holes with the increase of the age of lattice aprons.

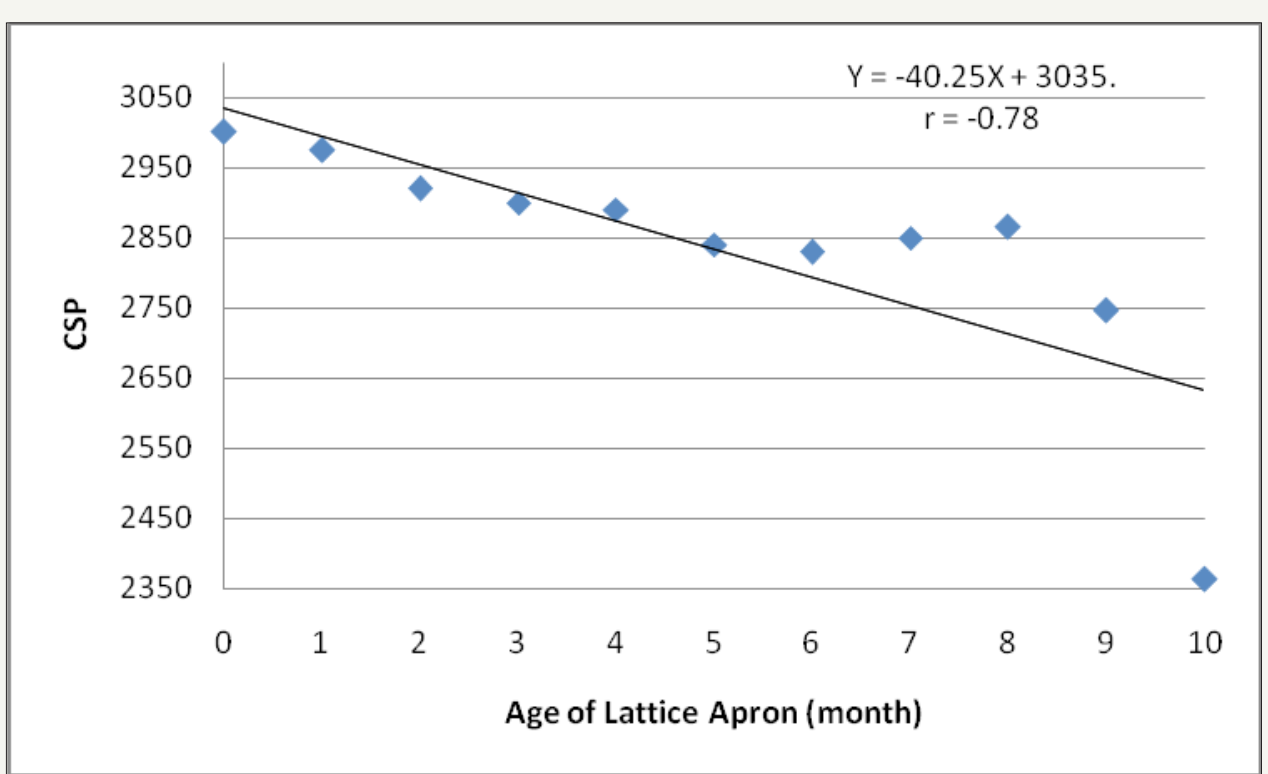

Figure 6: Relationship between CSP and age of lattice apron.

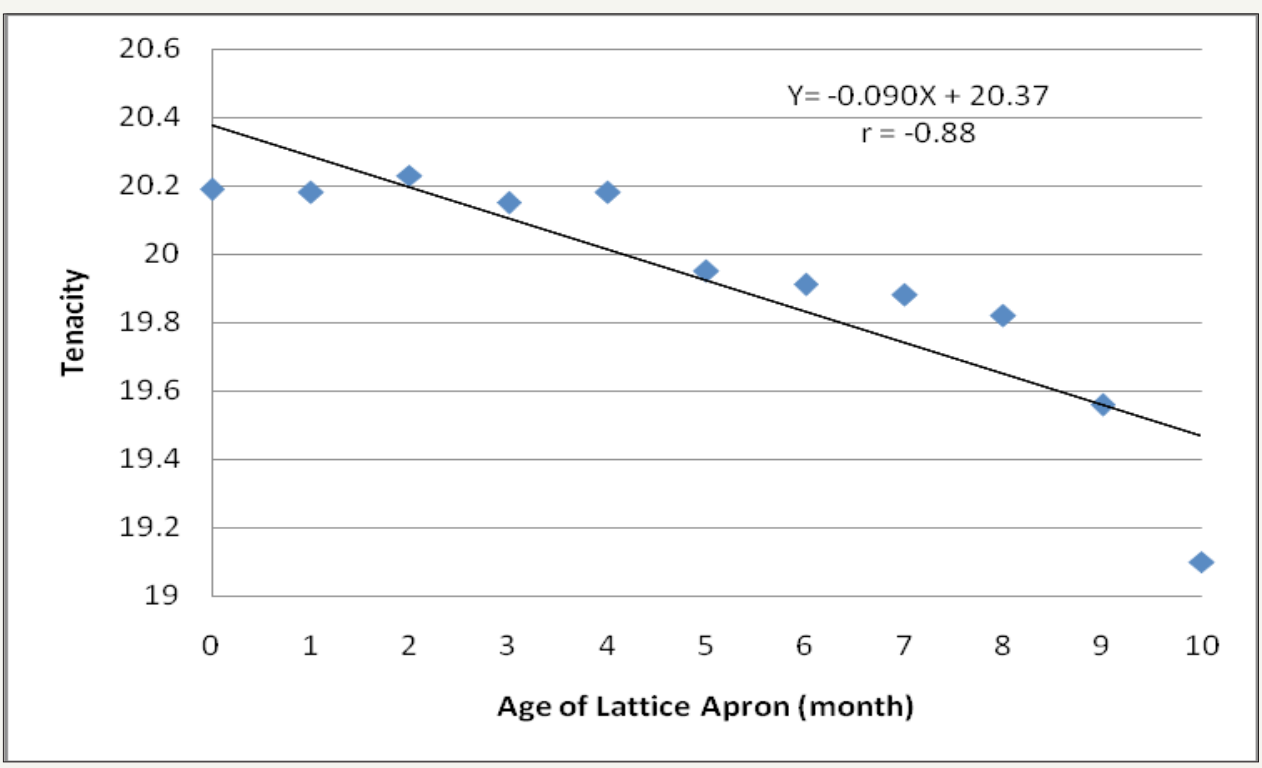

Figure 7: Relationship between tenacity and age of attice apron

\section{Construction of multiple linear regression equations}

Multiple linear regression analysis is mainly based on the relationship between more than one or additional independent variable with the dependent variable $[50,64,65]$. By using an above- mentioned variable, we get the multiple linear regression equations by using Microsoft Excel software

$\mathrm{Y}=-154.02+1.46 \mathrm{X}_{1}+0.03 \mathrm{X}_{2}+4.75 \mathrm{X}_{3}+0.02 \mathrm{X}_{4}-0.36 \mathrm{X}_{5+} 17.06 \mathrm{X} 6$ 


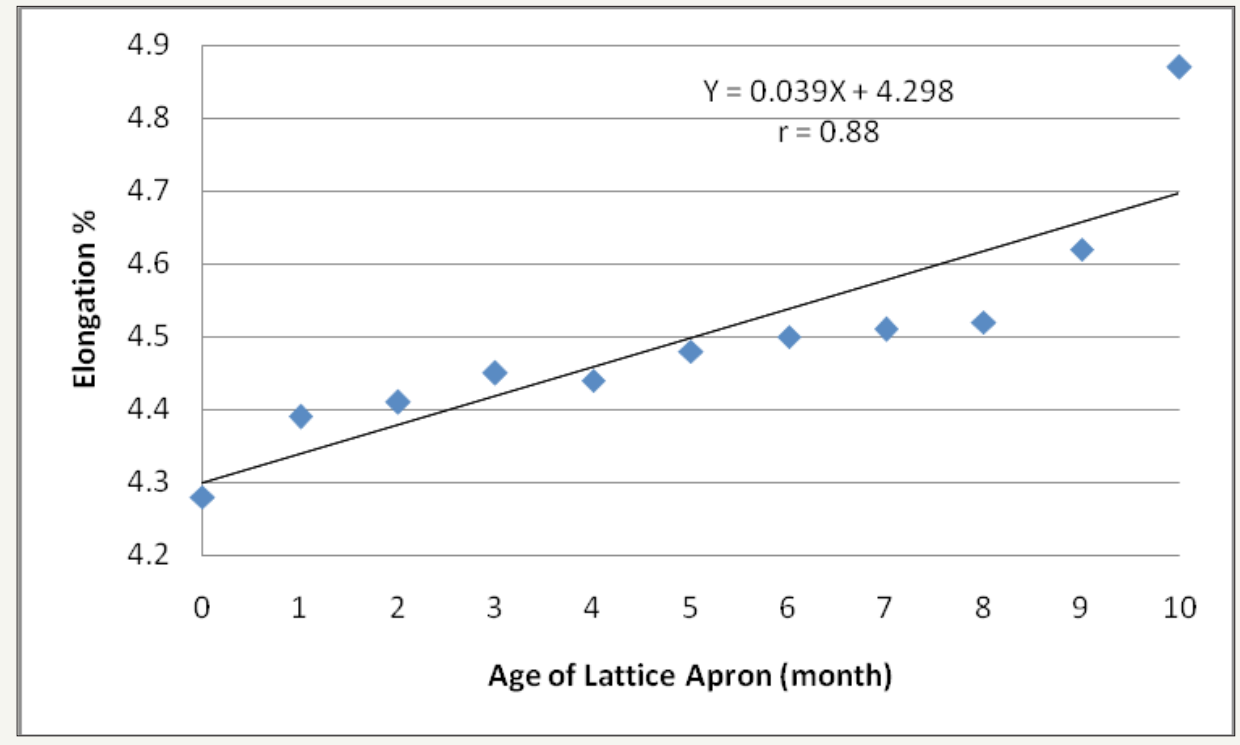

Figure 8: Relationship between elongation $\%$ and age of lattice apron.

Where $-154.02=$ intercept of the $y$-axis

$\mathrm{X}_{1}, \mathrm{X}_{2}, \mathrm{X}_{3}, \mathrm{X}_{4}, \mathrm{X}_{5}$, and $\mathrm{X}_{6}$ are the coefficient of independent variables

$1.46=$ coefficient of $\mathrm{U} \%\left(\mathrm{X}_{1}\right)$

$0.03=$ coefficient of IPI $\left(\mathrm{X}_{2}\right)$

$4.75=$ coefficient of Hairiness $\left(\mathrm{X}_{3}\right)$

$0.02=$ coefficient of $\operatorname{CSP}\left(\mathrm{X}_{4}\right)$

$-0.36=$ coefficient of Tenacity $\left(\mathrm{X}_{5}\right)$

17.06= coefficient of Elongation $\%\left(\mathrm{X}_{6}\right)$

The values of the positive and negative coefficient are indicated the increasing and decreasing trend of the quality profile of the compact yarns [66] with increasing the age of lattice aprons. For example, the positive value of the coefficient of unevenness of mass $\mathrm{U} \%$ (Figure 3) indicates the increasing of U\% with the increase of age of lattice aprons and the negative value of the coefficient of tenacity (Figure 7) expresses the decreasing of Tenacity with the increase of age of lattice aprons.

\section{Conclusions and Recommendation for Future Research}

Throughout the work, it was observed that with the increase of the age of the lattice aprons, the yarn quality parameters such as U\%, IPI, hairiness, CSP, and tenacity deteriorated with only the increment of elongation. Almost all the time the best result was found with fresh lattice aprons and almost the worst quality for the lattice aprons aged over 9 months. It can, therefore, be concluded that there is a significant correlation between the ages of the lattice aprons with yarn qualities because the coefficient of determination value was more than \pm 0.8 . The construction of multiple linear regression equations can be exclusively used to predict the yarn quality.
In future, an extensive research can be done by pair wise comparison of yarn quality with the age of lattice aprons with others parameters that are used in condensing device of Sussen and other compact spinning attachment by using Analytical Hierarchy Process (AHP) and other fuzzy logic.

\section{References}

1. Ahmad N, Hossen J, Ali SM (2018) Improvement of overall equipment efficiency of ring frame through total productive maintenance: a textile case. The International Journal of Advanced Manufacturing Technology 94(1-4): 239-256.

2. Khurshid MF, Nadeem K, Asad M, Chaudhry MA, Amanullah M (2013) Comparative analysis of cotton yarn properties spun on pneumatic compact spinning systems. Fibres and Textiles in Eastern Europe 101(5): 30-34.

3. Lord PR (2003) Hand book of yarn production. Wood head Publishing Limited, Cambridge England, England, UK.

4. Hossen J, Ahmad N, Ali SM (2017) An application of pareto analysis and cause-and-effect diagram (CED) to examine stoppage losses: a textile case from Bangladesh. The Journal of The Textile Institute 108(11): 2013-2020.

5. Qiu H, Zhang Y, Xu ZL, Ge MQ (2012) A novel method to reduce hairiness level of ring spun yarn. Fibers and Polymers 13(1): 104-109.

6. Dou HP, Liu SR (2011) Trajectories of fibers and analysis of yarn quality for compact spinning with pneumatic groove. The Journal of the Textile Institute 102(8): 713-718.

7. Purushothama B (2011) A practical guide on quality management in spinning. Woodhead Publishing India Pvt. Ltd., New Delhi, India.

8. Krause HW (1985) Staple fibre spinning systems. The Journal of The Textile Institute 76(3): 185-195.

9. Soltani P, Johari MS (2012) A study on siro-, solo-, compact- and conventional ring-spun yarns. Part I: Structural and migratory properties of the yarns. The Journal of The Textile Institute 103(6): 622-628.

10. Taylor P, Liu X, Liu W, Zhang H, Su X (2014) Journal of the textile institute research on pneumatic compact spun yarn quality. The Journal of The Textile Institute 102(8): 713-718. 
11. Ishtiaque SM, Subramani P, Kumar A, Das BR (2009) Structural and tensile properties of ring and compact plied yarns. Indian Journal of Fibre and Textile Research 34(3): 213-218.

12. Basal G (2006) Comparison of properties and structures of compact and conventional spun yarns. Textile Research Journal 76(7): 567-575.

13. Çelik P, Kadoğlu H (2004) A research on the compact spinning for long staple yarns. Fibres and Textiles in Eastern Europe 12(4): 27-31.

14. Mcloughlin J, Towers N (2005) Effective total quality management in the textile fashion retail supply chain: A pilot survey of the UK textile manufacturers. The Journal of the Textile Institute 96(2): 87-92.

15. Holmlund M (2007) Suggesting and comparing different scopes on quality management: Production, service, relationship, and network Total Quality Management \& Business Excellence 18(8): 847-859.

16. Kiran M, Mathew C, Kuriakose J (2013) Root cause analysis for reducing breakdowns in a manufacturing industry. International Journal of Emerging Technology and Advanced Engineering 3(1): 211-216.

17. Andersson R, Manfredsson P, Lantz B (2015) Total productive maintenance in support processes: An enabler for operation excellence. Total Quality Management and Business Excellence 26(9-10): 10421055.

18. Tyagi GK, Kumar R (2009) Influence of spinning variables on migration parameters of compact and ring-spun yarns. Indian Journal of Fibre and Textile Research 34(4): 333-337.

19. Yang J, Wang J, Bu H, Fu T, Xi Q et al. (2009) Mechanical analysis on constant cross-section segment of fiber band in condensing zone during compact spinning. The Journal of the Textile Institute 100(5): 451-456.

20. Goktepe F (2006) A comparison of compact yarn properties produced on different systems. Textile Research Journal 76(3): 226-234.

21. Lawrence CA (2010) Advances in yarn spinning technology. Woodhead Publishing Limited, Cambridge, England, UK.

22. Stalder A, Rusch A (2002) Int Text Bull, 1: 42.

23. Liu XJ, Liu WL, Zhang H, Su XZ (2015) Research on pneumatic compact spun yarn quality. The Journal of the Textile Institute 106 (4): 431-442.

24. Hossen J, Saha SK (2011) Selection of appropriate ring traveller number for different count of cotton hosiery yarn. International Journal of Engineering \& Technology 11(6): 70-76.

25. Yazdi AA (2011) Effects of directed movement of fibres in a twist triangle on yarn quality. The Journal of the Textile Institute 102(3): 263-271.

26. Sriprateep K, Bohez ELJ (2009) A new computer geometric modelling approach of yarn structures for the conventional ring spinning process. The Journal of the Textile Institute 100(3): 223-236.

27. Klein W (2012) The technology of short-staple spinning. The Textile Institute, Manchester, UK.

28. Stritof A (2003) Compact spinning for improved quality of ring-spun yarns. Fibres and Textiles in Eastern Europe 11(4): 30-35.

29. Li W, Su X, Zhang Y, Xie C, Wei Q (2015) Evaluation of the correlation between the structure and quality of compact blend yarns. Fibres and Textiles in Eastern Europe 6(114): 55-67.

30. Su X, Gao W, Liu X (2015) Numerical simulation of flow field in complete condensing spinning: effects of suction unit and guiding device. Journal of the Textile Institute 107(7): 811-824.

31. Cheng KPS, Yu C (2003) A study of compact spun yarns. Textile Research Journal 73(4): 345-349.

32. Das A, Kothari VK, Sadachar A (2007) Study on characteristics of compact yarns under dynamic state. Fibers and Polymers 8(1): 111-115.
33. Su X, Gao W, Liu X, Xie C, Xu B (2016) Theoretical study of the effects of the general division of a ring spinning triangle on fibre tension. Fibres and Textiles in Eastern Europe 24(2): 37-43.

34. Stalder H (2000) New spinning process comforspin. Melliand International 6(1): 24-25.

35. Cotter RJ (2003) United states patent 1(12):6-9.

36. Lawrence CA (2003) Fundamentals of spun yarn technology. CRC Press, Washington DC, New York, USA.

37. Liu XJ, Su XZ (2014) Numerical simulation of three dimensional flow field in compact spinning with Hollow Roller. International Journal of Clothing Science and Technology 26(2): 131-144

38. Kremenáková D, Novácková J, Voborová J (2003) Compact yarnstructure and Properties, In Proceedings of the TEX- SCI Conference: 215-218.

39. Yilmaz D, Goktepe F, Goktepe O, Kremenakova D (2007) Packing density of compact yarns. Textile Research Journal 77(9): 661-667.

40. Loganathan R, Mallyah M, Ramachandran T (2009) Influence of D-type slot compact system on migration properties of the carded compact yarn. Journal of Engineered Fibers and Fabrics 4(4): 7-13.

41. Wang W (2009) Research on production processes and properties of ultra-fine compact-siro spun yarns. MD Thesis. Suzhou University, China.

42. Zou ZY, Cheng L, Di Hua ZH (2010) A numerical approach to simulate fiber motion trajectory in an airflow field in compact spinning with a perforated drum. Textile Research Journal 80(5): 395-402.

43. Zhuan YZ, Yun DZ, Zhi HH, Wang Y, Cheng LD (2010) Studies of flexible fiber trajectory and its pneumatic condensing mechanism in compact spinning with lattice apron. Textile Research Journal 80(8): 712-719.

44. Lu L (2013) Study on the condensing mechanism and key components of compact-siro spun with lattice apron. MD Thesis. Donghua University, China.

45. Han C, Wei M, Xue W, Cheng L (2015) Numerical simulation and analysis of airflow in the condensing zone of compact-siro spinning. Textile Research Journal 85(14): 1506-1519.

46. Fu T, Yang J, Cheng G, Chen N, Qiu Y (2017) Mechanical modeling of an arc-shaped suction slot for compact spinning and analysis of additional twists. Textile Research Journal.

47. Khurshid MF (2017) Comparative analysis of siro yarn properties spun on ring and pneumatic compact spinning systems. Industria Textila 68(1): 245-249.

48. Liu X, Su X, Zhang H (2017) Effects of lattice apron density on yarn qualities in Four-line compact spinning system. Journal of the Textile Institute 108(4): 511-521.

49. Mustafa E, Üreyen HK (2007) The prediction of cotton ring yarn properties from AFIS fibre properties by using linear regression models. Fibres \& Textiles in Eastern Europe 4(63): 63-67.

50. Richard $\mathrm{T}$ (1990) Interpretation of the correlation-coefficient-a basic review. Journal of Diagnostic Medical Sonography 6(1): 35-39.

51. Lind DA, Marchal WG, Wathen SA (2016) Statistical techniques in business \& economics. McGraw-Hill/Irwin, New York, USA.

52. Abebe A, Daniels J, Mc Kean JW, Kapenga JA (2001) Statistics and data analysis. Statistical Computational Lab, Western Michigan University, Kalamazoo, USA.

53. Edminister J (1995) Theory and problems of eletromagnetcs. McgrawHill Book Company, New York, USA.

54. Dixon WJ, Massey FJ (1950) Introduction to statistical analysis. McgrawHill Book Company, New York, USA. 
55. Erdfelder E, Faul F, Buchner A, Lang AG (2009) Statistical power analyses using G*Power 3.1: Tests for correlation and regression analyses. Behavior Research Methods 41(4): 1149-1160.

56. Ureyen ME, Kadoglu H (2006) Regressional estimation of ring cotton yarn properties from HVI fiber properties. Textile Research Journal 76(5): 360-366.

57. Fattahi S, Ravandi SAH, Taheri SM (2011) Two-way prediction of cotton yarn properties and fiber properties using multivariate multiple regression. Journal of the Textile Institute 102(10): 849-856.

58. Hossen J, Saha SK (2012) Assessment of the process stability of cotton yarn count by means of variable and attribute control chart on a spinning mill. Journal of Innovation and Development Strategy 6(1): 32-39.

59. Saha SK, Hossen J (2011) Optimization of doubling at draw frame for quality of carded ring yarn. International Journal of Engineering \& Technology 11(6): 92-97.

60. Majumdar A, Majumdar PK, Sarkar B (2005) Application of an adaptive neuro fuzzy system for the prediction of cotton yarn strength from HVI fiber properties. The Journal of the Textile Institute 96(1): 55-60.
61. Saville BP (1999) Physical testing of textiles. CRC Press, Washington DC, New York, USA.

62. Majumdar PK, Majumdar A (2004) Predicting the breaking elongation of ring spun cotton yarns using mathematical and ANN models. Textile Research Journal 74(7): 652-655.

63. Morton WE, Hearle JWS (2008) Physical properties of textile fibres. New York, USA.

64. Ureyen ME, Gürkan P (2008a) Comparison of ANN and linear regression models for prediction of ring spun yarn properties, part I: Prediction of yarn tensile properties. Fibers and Polymers 9(1): 87-91.

65. Ureyen ME, Gürkan P (2008b) Comparison of ANN and linear regression models for prediction of ring spun yarn properties, part II: Prediction of yarn hairiness and unevenness. Fibers and Polymers 9(1): 92-96.

66. Pal S, Gauri SK (2010) Multi-response optimization using multiple regression-based weighted signal-to-noise ratio (MRWSN). Quality Engineering 22(4): 336-350.
Creative Commons Attribution 4.0 International License

For possible submissions Click Here

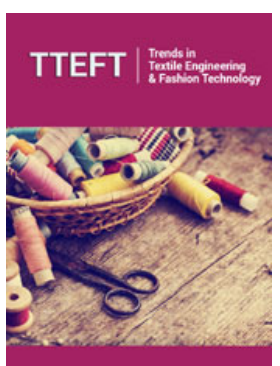

Trends in Textile Engineering \& Fashion Technology

\section{Benefits of Publishing with us}

- High-level peer review and editorial services

- Freely accessible online immediately upon publication

- Authors retain the copyright to their work

- Licensing it under a Creative Commons license

- Visibility through different online platforms 